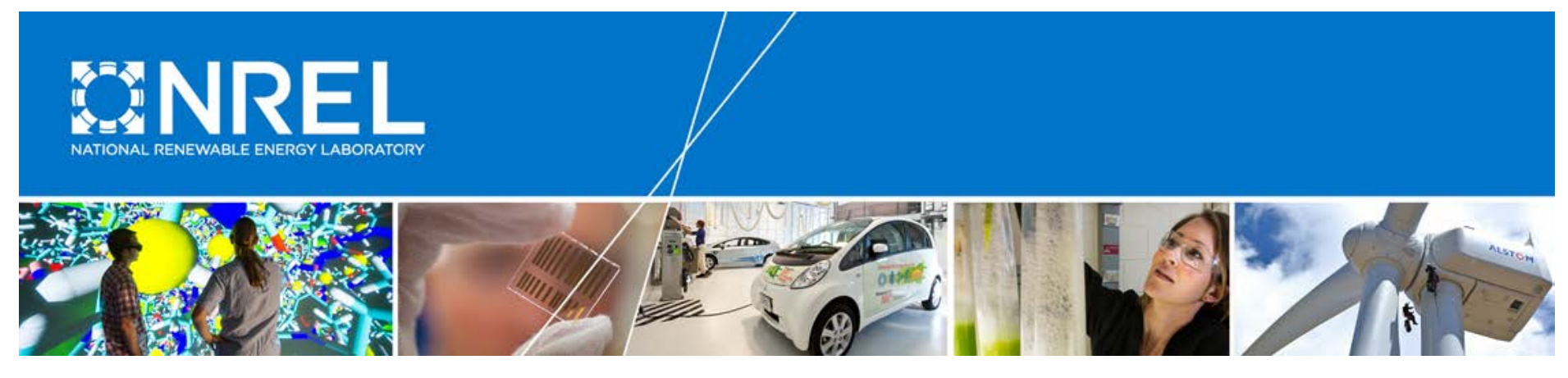

\title{
Energy Storage Opportunities and Capabilities in a Type 3 Wind Turbine Generator
}

\section{Preprint}

Eduard Muljadi, Vahan Gevorgian, and Andy Hoke National Renewable Energy Laboratory

To be presented at the 2016 IEEE Energy Conversion Congress and Exposition Milwaukee, Wisconsin

September 18-22, 2016

(C) 2016 IEEE. Personal use of this material is permitted. Permission from IEEE must be obtained for all other uses, in any current or future media, including reprinting/republishing this material for advertising or promotional purposes, creating new collective works, for resale or redistribution to servers or lists, or reuse of any copyrighted component of this work in other works.

NREL is a national laboratory of the U.S. Department of Energy Office of Energy Efficiency \& Renewable Energy Operated by the Alliance for Sustainable Energy, LLC

This report is available at no cost from the National Renewable Energy Laboratory (NREL) at www.nrel.gov/publications.

\section{Conference Paper}

NREL/CP-5D00-66394

September 2016 


\section{NOTICE}

The submitted manuscript has been offered by an employee of the Alliance for Sustainable Energy, LLC (Alliance), a contractor of the US Government under Contract No. DE-AC36-08GO28308. Accordingly, the US Government and Alliance retain a nonexclusive royalty-free license to publish or reproduce the published form of this contribution, or allow others to do so, for US Government purposes.

This report was prepared as an account of work sponsored by an agency of the United States government. Neither the United States government nor any agency thereof, nor any of their employees, makes any warranty, express or implied, or assumes any legal liability or responsibility for the accuracy, completeness, or usefulness of any information, apparatus, product, or process disclosed, or represents that its use would not infringe privately owned rights. Reference herein to any specific commercial product, process, or service by trade name, trademark, manufacturer, or otherwise does not necessarily constitute or imply its endorsement, recommendation, or favoring by the United States government or any agency thereof. The views and opinions of authors expressed herein do not necessarily state or reflect those of the United States government or any agency thereof.

This report is available at no cost from the National Renewable Energy Laboratory (NREL) at www.nrel.gov/publications.

Available electronically at SciTech Connect http:/www.osti.gov/scitech

Available for a processing fee to U.S. Department of Energy and its contractors, in paper, from:

U.S. Department of Energy

Office of Scientific and Technical Information

P.O. Box 62

Oak Ridge, TN 37831-0062

OSTI http://www.osti.gov

Phone: 865.576.8401

Fax: 865.576.5728

Email: reports@osti.gov

Available for sale to the public, in paper, from:

U.S. Department of Commerce

National Technical Information Service

5301 Shawnee Road

Alexandria, VA 22312

NTIS http://www.ntis.gov

Phone: 800.553 .6847 or 703.605 .6000

Fax: 703.605.6900

Email: orders@ntis.gov 


\title{
Energy Storage Opportunities and Capabilities of a Type 3 Wind Turbine Generator
}

\author{
E. Muljadi, Fellow, IEEE, V. Gevorgian, Member, IEEE, and A. Hoke, Member, IEEE
}

\begin{abstract}
Wind power plants and other renewable power plants with power electronic interfaces are capable of delivering frequency response (both governor and/or inertial response) to the grid by a control action; thus, the reduction of available online inertia as conventional power plants are retired can be compensated by designing renewable power plant controls to include frequency response. The source of energy to be delivered as inertial response is determined by the type of generation and control strategy chosen.

The cost of energy storage is expected to drop over time, and global research activities on energy storage are very active, funded both by the private industry and governments. Different industry sectors (e.g., transportation, energy) are the major drivers of the recent storage research and development.

This work investigates the opportunities and capabilities of deploying energy storage in renewable power plants. In particular, we focus on wind power plants with doubly-fed induction generators, or Type 3 wind turbine generator (WTGs). We find that the total output power of a system with Type 3 WTGs with energy storage can deliver a power boost during inertial response that is up to $45 \%$ higher than one without energy storage without affecting the torque limit, thus enabling an effective delivery of ancillary services to the grid.
\end{abstract}

Index Terms-adjustable speed, ancillary services, doubly-fed induction generator, energy storage, frequency response, variable speed, wind power plant, wind turbine.

\section{INTRODUCTION}

$\mathrm{T}$ HE total inertia stored in all rotating masses (synchronous generators, induction motors, etc.) connected to a power system grid is an essential force that keeps the system stable after disturbances. Power systems have been experiencing reduced inertia for the past few decades [1]. This trend will continue as conventional power plants are retired and the level of renewable generation (e.g., wind and solar) increases.

Wind power plants (WPPs) and other renewable power plants with power electronic interfaces are capable of delivering frequency response (both droop and/or inertial response) by a control action; thus, the reduction in available online inertia can be compensated by designing the plant control to include frequency response [2], [3]. The source of energy to deliver inertial response in a wind turbine generator (WTG) can be derived from the kinetic energy of the rotating blades or from energy storage. The opportunity to use energy storage in a renewable power plant is found in two locations: one is at the plant level at the low side of the substation; and the other is at the generator level (at the DC bus in parallel with the DC capacitor), as shown in Fig. 1. The green arrows show the possible directions of power flow when the turbine is online or offline.

The capability to deliver output power from energy storage at the point of interconnection is determined by the power rating of the power converter at the turbine level. The maximum length of time the stored energy can be delivered is determined by the energy content and the rate of the power output. This is very straightforward; thus, it will not be discussed further.

This report focuses only on Type 3 WTGs. Detailed dynamic model equations to simulate the DFIG system including storage can be found in [4], [5]. Note that the size of the energy storage depends on the requirements and the techno-economic analysis of the project considered. In this paper, we consider only the technical aspects, not the economic aspects. In practical implementation, the battery sizing must be treated and analyzed in more detail based on the need and importance. Many references are available to compute the battery sizing [6], [7].

This paper is arranged as follows: Section II presents the steady-state behavior of Type 3 WTGs and energy storage, and Section III presents the dynamic simulation behavior. Finally, Section IV presents the conclusion.

\section{TYPE 3 WTGS AND ENERGY STORAGE CONSIDERATION}

Since the induction machine was invented by Nikola Tesla in 1883, it has been preferred for extensive industrial applications because of its numerous advantages. One such advantage of a wound-rotor induction machine is that it allows for variable-speed operation with a relatively simple design modification-i.e., by inserting a variable rotor resistance into the rotor winding via a three-phase slip ring. Recently, the use of wound-rotor induction machines has been revived in the form of induction generators for wind turbine applications. With the power converter connected to the rotor winding, the induction generator can be operated at variable speed using a partial-rating power converter. This configuration is referred to as a doubly-fed induction generator (DFIG).

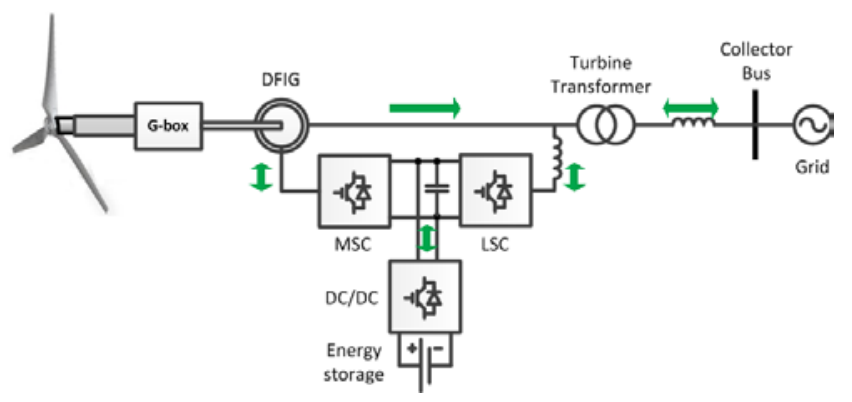

Fig. 1. Physical diagram of a Type 3 WTG with the power flow direction

\section{1) Basic Equations}

From the per-phase equivalent circuit of a DFIG, which is shown in Fig. 2, we can derive the equations to determine the size of the power converter needed. 


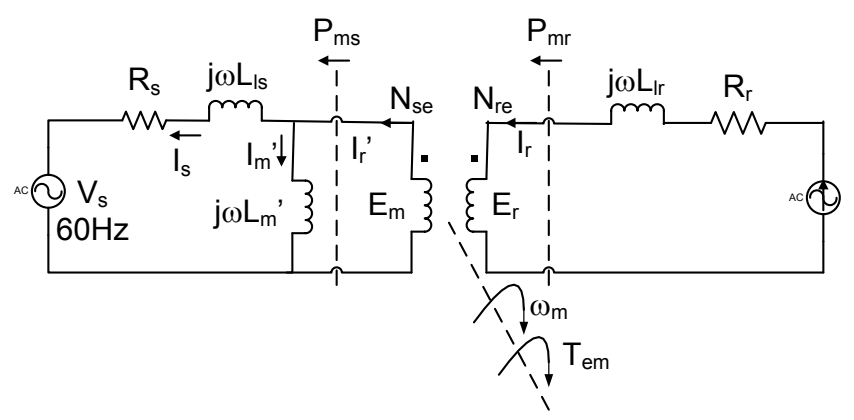

Fig. 2. Per-phase equivalent circuit of the induction generator

From the equivalent circuit, the induced rotor emf, $\mathrm{E}_{\mathrm{r}}$, is proportional to the winding ratio and to the rotor frequency. In a locked rotor condition (slip $=1$ ), the stator-to-rotor winding relationship is similar to a transformer. As the slip gets smaller, the rotor voltage decreases. The relationship between the stator emf, $\mathrm{E}_{\mathrm{s}}$, and slip can be written as:

$$
\frac{E_{m r}}{E_{m s}}=\mathrm{s} \frac{N_{r e}}{N_{s e}}\left\langle\theta_{e}\right.
$$

The current ratio is not affected by the rotor frequency, and it can be written as:

$$
\frac{\boldsymbol{I}_{r}}{\boldsymbol{I}_{\boldsymbol{s}}}=\frac{N_{s e}}{N_{r e}}\left\langle\theta_{e}\right.
$$

The ratio of the actual rotor impedance to the stator-referred rotor impedance is given by:

$$
\frac{Z_{r}}{Z_{r^{\prime}}}=s\left[\frac{N_{r e}}{N_{s e}}\right]^{2}
$$

The useful active power at the stator side can be computed as:

$$
P_{m s}=\operatorname{Re}\left[\boldsymbol{I}_{\boldsymbol{m s}} \boldsymbol{E}_{\boldsymbol{m} s}{ }^{*}\right]
$$

The real power at the rotor side can be computed as:

$$
P_{m r}=\operatorname{Re}\left[\boldsymbol{I}_{\boldsymbol{m r}} \boldsymbol{E}_{\boldsymbol{m r}}{ }^{*}\right]
$$

By substitution, we get:

$$
P_{m r}=\operatorname{Re}\left[\mathrm{s} \boldsymbol{I}_{\boldsymbol{m s}} \boldsymbol{E}_{\boldsymbol{m s}}{ }^{*}\right]
$$

Or:

$$
P_{m r}=s P_{m s}
$$

Of the total air gap power of the generator, only a small fraction is dissipated in the rotor circuits. The total electrical output power generated to the grid is given by:

$$
P_{\text {total }}=\left(P_{m s}-P_{m r}\right)=(1-s) P_{m s}
$$

Thus, the total power generated by the turbine is converted into electrical power delivered to the grid; the majority is delivered via the stator winding, and the rest via the rotor output power. For example, assuming that the turn ratio of the stator-to-rotor winding is one, the DFIG needs to be operated at $+30 \%$ slip. The power converter to be used must have a rated voltage of approximately $30 \%$ and rated current of $100 \%$. The implication is that using a DFIG in variable speed with slip variation from $-30 \%$ to $+30 \%$ requires the size of the power converter to be approximately $30 \%$ of the rated power of the induction generator.

\section{2) Power Converter and Generator Control}

The power converter and the DFIG are controlled based on the equations derived in the previous section. The reference power is the commanded power output of the turbine. The DFIG has two separate paths of generation: the stator output power and the rotor output power. The output power from the stator winding (always flowing out of the stator to the grid) can be described as:

$$
P_{m s}=\frac{P_{\text {total }}}{(\mathbf{1}-\boldsymbol{s})}
$$

Stator power generated by the DFIG as a function of the total power is illustrated in Fig. 3. As shown, the variation of the stator power is very narrow. For example, in the span of 0.2 p.u. total power variation, the stator power varies by approximately $2 \%$.

The rotor power can be computed as:

$$
P_{m r}=\frac{s}{(\mathbf{1}-\boldsymbol{s})} P_{\text {total }}
$$

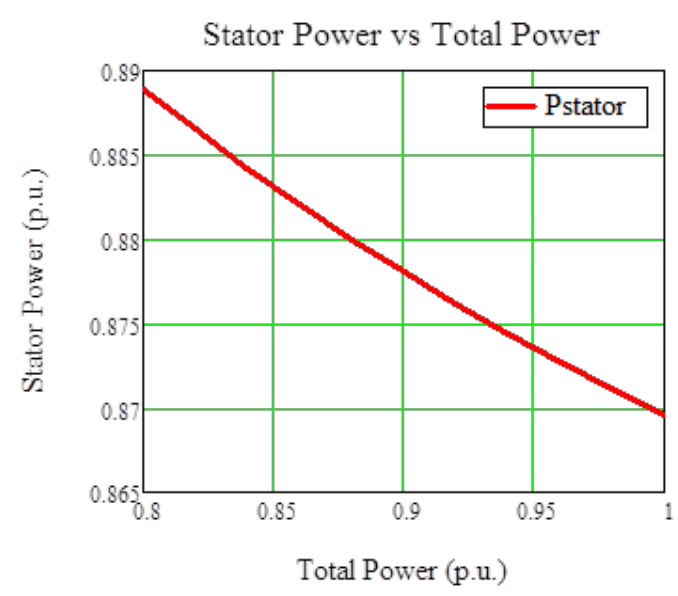

Fig. 3. Stator power as a function of total power

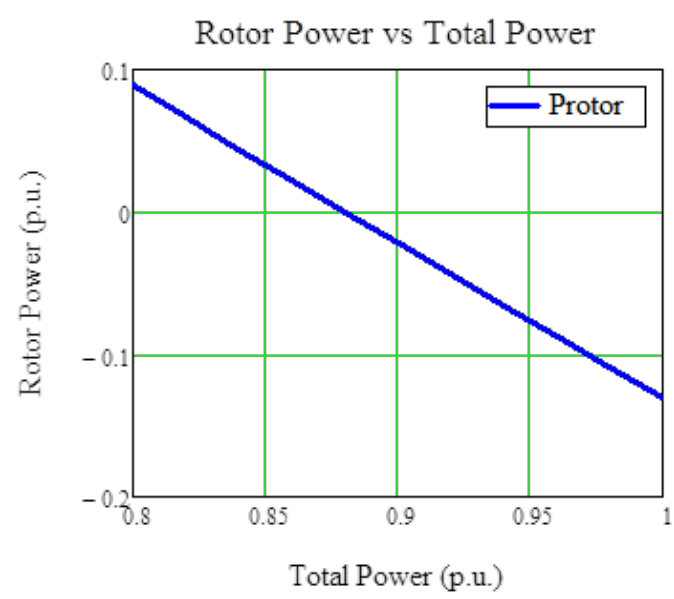

Fig. 4. Rotor power as a function of total power

Thus, the total power entering the rotor winding of the DFIG is as shown in Fig. 4. Note that the sign of rotor power changes from positive in subsynchronous operation, indicating that the power enters the rotor winding from the grid, into negative in supersynchronous operation, indicating that the power leaves the rotor winding into the grid. 
As shown, the variation of the rotor power is linear with respect to the total power. For example, in the span of 0.2 p.u. total power variations, the rotor power varies by approximately $\pm 12 \%$. Note that the rotor power becomes zero at the synchronous speed (slip $=0)$. Below the synchronous speed, the rotor power flows from the grid into the rotor winding; above the synchronous speed, the rotor power flows from the rotor winding to the grid.

As shown in Fig. 5, the machine-side converter (MSC) is used to control the commanded stator output power $\left(\mathrm{P}_{\text {stator-ref }}\right)$ based on the calculated reference that will optimize the turbine. The reactive power is controlled to follow the commanded reactive power output of the stator winding $\left(\mathrm{Q}_{\text {stator-ref }}\right)$. The real power component of the stator current, $\mathrm{I}_{\mathrm{pS}}$, and the reactive power component of the stator current, $\mathrm{I}_{\mathrm{qS}}$, are controlled by the MSC.

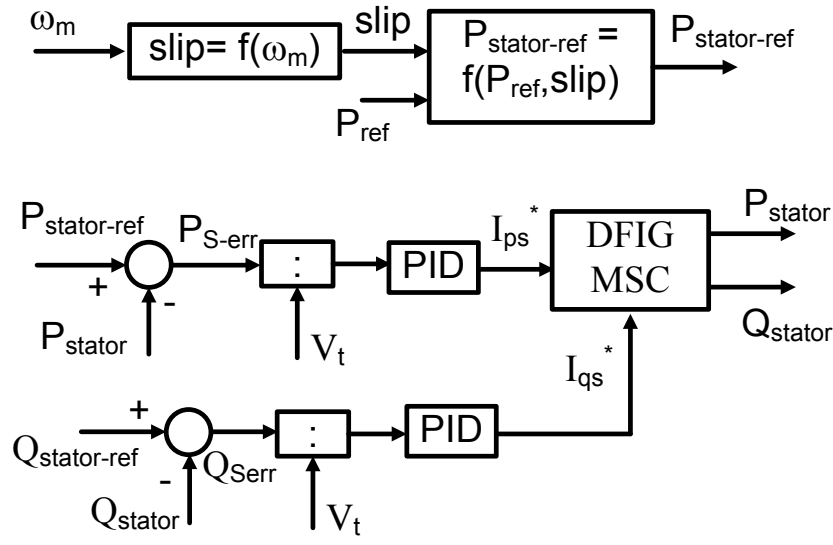

Fig. 5. Simplified diagram of MSC

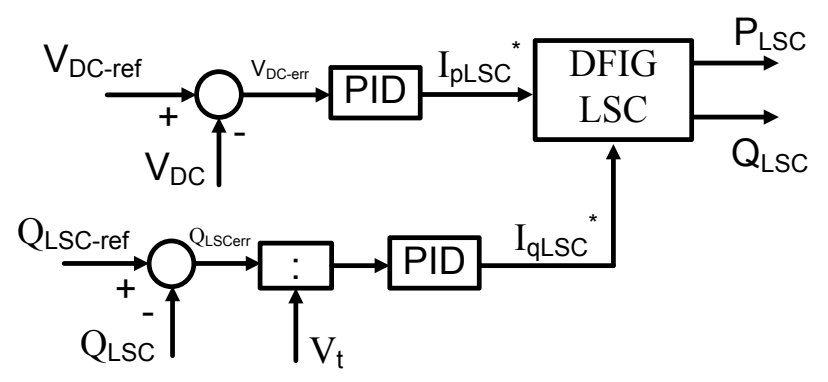

Fig. 6. Simplified diagram of LSC

As shown in Fig. 6, the line-side converter (LSC) is controlled to maintain the $\mathrm{DC}$ bus constant and the reactive power contribution from the LSC to the grid. Note that by controlling the DC bus constant, the LSC automatically transfers the rotor power to the grid. The real power component of the current, $\mathrm{I}_{\mathrm{pLSC}}$, is controlled to maintain the DC bus voltage, whereas the reactive power component of the current, $\mathrm{I}_{\mathrm{qLSC}}$, is used to control the requested reactive power from the LSC.

\section{3) Operation without Energy Storage}

The operation of a power converter and the DFIG without energy storage is governed by (9)-(12). In the stator circuit, the direction output power flow, $\mathrm{P}_{\mathrm{ms}}$, is always coming out of the stator terminals. On the other hand, the output power of the rotor circuit has a bidirectional power flow.

Operating a power converter without energy storage must follow the rule that the power in is equal to the power out both in sign and in magnitude. Thus, the power flowing into the rotor $\left(\mathrm{P}_{\mathrm{mr}}\right)$ is equal to the power entering the power converter from the grid $\left(\mathrm{P}_{\mathrm{LSC}}\right)$. For subsynchronous and supersynchronous operations:

$$
P_{m r}=P_{L S C}
$$

a) $C_{p_{-} \max }$ Operation without Energy Storage

Normal operation of a power converter and the DFIG without energy storage is governed by the equations for maximizing energy capture of the wind turbine $\left(\mathrm{C}_{\mathrm{p}_{-} \max }\right.$ operation). The total power is represented by:

$$
P_{\text {tot }}=P_{\max } \omega^{3}
$$

The stator and rotor power can be found by (7) and (8).

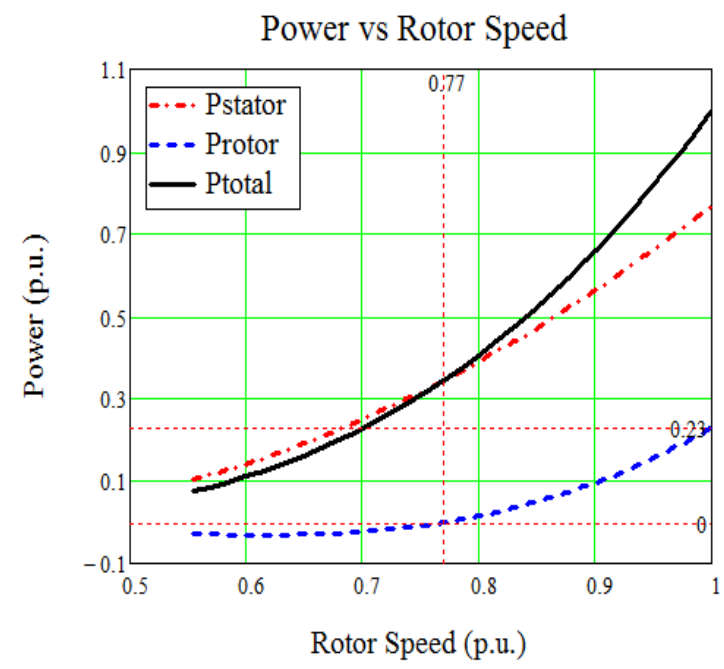

Fig. 7. $\mathrm{P}_{\text {stator }}, \mathrm{P}_{\text {rotor }}$, and $\mathrm{P}_{\text {total }}$ as a function of rotor speed for normal $\left(\mathrm{C}_{\mathrm{pmax}}\right)$ operation

Fig. 7 illustrates the power division between the stator and the rotor circuits. In subsynchronous rotor speed (slip $=0.3$ through slip $=0$ ), the output power from the rotor is negative (the power entering the rotor circuit from the grid); in supersynchronous operation (slip $=0$ through slip $=-0.3$ ) the output power from the rotor is positive (out of the rotor winding). The total output power is shown by the solid black line.

\section{b) $T_{\max }$ Operation without Energy Storage}

The maximum torque operation of the power converter and the DFIG without energy storage is governed by:

$$
P_{\text {tot }}=T_{\max } \omega
$$

This operation is chosen to maximize the output power during the frequency response-for example, to maximize the output power contribution from the turbine without exceeding the maximum torque and thus preserve the gearbox and other mechanical components between the grid and the blades. Using (13), (9), and (10), we can get the power division between the rotor and stator windings, as shown in Fig. 8. 


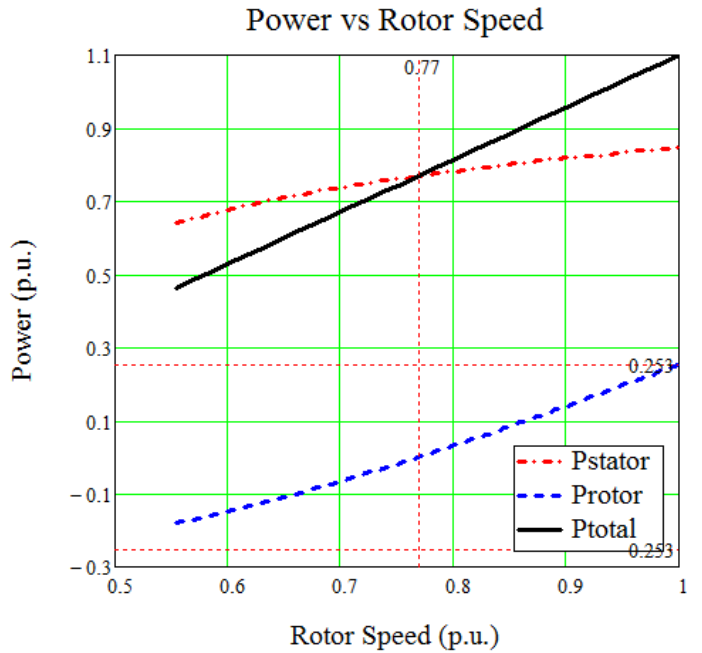

Fig. 8. $\mathrm{P}_{\text {stator }}, \mathrm{P}_{\text {rotor }}$, and $\mathrm{P}_{\text {total }}$ as a function of rotor speed for maximum torque operation

Comparing Fig. 7 to Fig. 8, the major difference is in the operation in the subsynchronous region, where the power flowing into the rotor circuits is much larger than it is in normal operation. The power converter must be sized to accommodate the $10 \%$ overload to provide a power boost during the inertial response. Thus, the size is now 0.253 p.u. instead of 0.23 p.u., as it is in normal $\left(\mathrm{C}_{\mathrm{p}_{-} \text {max }}\right)$ operation.

\section{4) Operation with Energy Storage}

With the presence of energy storage, the output power of the LSC $\left(\mathrm{P}_{\mathrm{LSC}}\right)$ is independent of the output power from the rotor into or out of the rotor circuit. Fig. 9 shows the comparison of two systems of DFIG generations (with and without storage). Equation (13) can be rewritten to include energy storage, as follows:
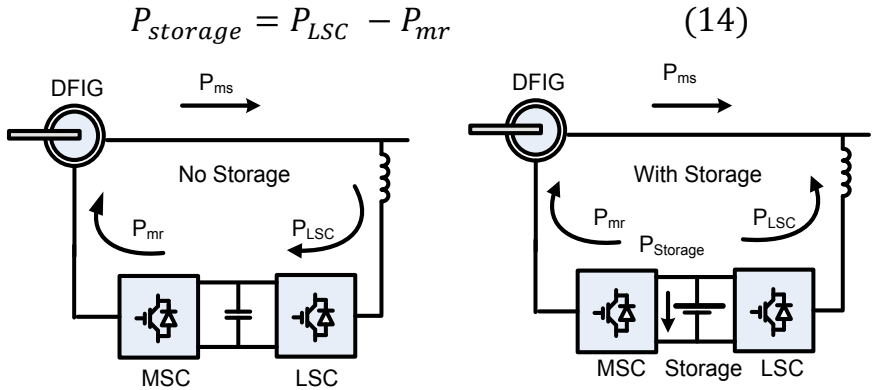

Fig. 9. Possible power flow directions in the stator and rotor circuits and the output power from the LSC for two systems: No Storage or With Storage

The power converter and the DFIG are controlled based on the equations derived in the previous section; however, with the presence of storage, there is freedom to release the storage power provided that the power rating of the LSC is not exceeded and the energy content is not depleted to an unsafe level. Thus, the output power of the LSC is controllable by controlling the output of the storage. This is a significant advantage - with energy storage on the DC bus, a DFIG can deliver sizable additional output power to support the grid during frequency dips (to provide inertial response).

From the point of view of electric machines, the operation presented in Fig. 8 is the same as the operation presented in
Fig. 10 (i.e., the DFIG is operated at maximum torque). However, from the perspective of the power converter, the energy storage enables the LSC of the DFIG to deliver the maximum possible output power $(+0.253$ p.u.) regardless of the rotor speed.

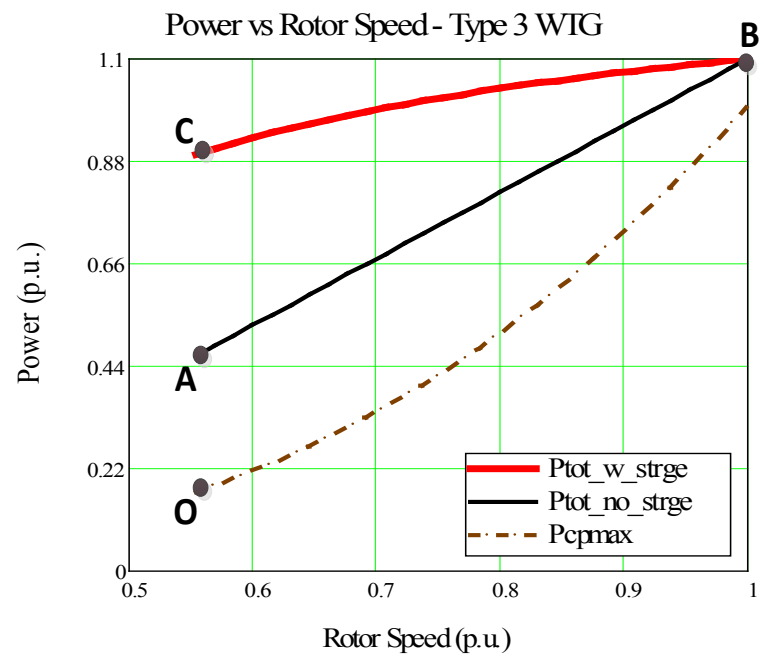

Fig. 10. $\mathrm{P}_{\text {cpmax }}, \mathrm{P}_{\text {total }}$ without storage and $\mathrm{P}_{\text {total }}$ with storage as a function of rotor speed for maximum torque operation

Operation without energy storage dictates that the $\mathrm{P}_{\mathrm{LSC}}$ is tied to the rotor power. Comparing the $\mathrm{P}_{\mathrm{LSC}}$ shows that there is a significant addition of output power from the additional energy storage (refer to the area bounded by points A, B, and $\mathrm{C}$ in Fig. 10). At the lower wind speed, without energy storage, the system can only deliver maximum output power of 0.45 p.u. (at a rotor speed of 0.55 p.u.). In comparison, a system with energy storage can deliver maximum output power of 0.9 p.u. at the same rotor speed. For example, under normal conditions, the WTG operates at Point O following the $\mathrm{C}_{\mathrm{pmax}}$ operation (brown dashed-dotted line). When the WTG is commanded to generate inertial response, the operating point of the generator can go from Point $\mathrm{O}$ to Point $\mathrm{C}$, instead of from Point $\mathrm{O}$ to Point $\mathrm{A}$. This additional output power (A to C) significantly boosted the capability of the DFIG to support the grid frequency in time of need.

The thick red line in Fig. 10 is the total output power that can be delivered when the DFIG is equipped with energy storage in the DC bus. The difference between the thin black line and the thick red line is the additional power capability for the system with the energy storage. Note that in subsynchronous operation, the storage must supply both the power into the rotor circuit and the power into the LSC, but during supersynchronous operation, it has to deliver power only to the LSC. Thus, the storage power capability has to be larger than the LSC power rating.

\section{CONCLUSIONS}

DFIG (Type 3) WTGs are currently the most popular WTGs installed on WPPs. The advantage of a DFIG is that its power converter is much smaller than the total rating of the WTG because it is used only to convert the slip power of the DFIG; thus, the capability to operate in an overload condition 
is also limited. DFIGs can be controlled to provide inertial response during frequency dips on the grid.

This paper explored the opportunity to use energy storage on a DFIG to take advantage of the nature of its generation. It is assumed that the DFIG is built with $\pm 30 \%$ operating slip. The energy storage on the DC bus of a DFIG enables the WTG to deliver up to $45 \%$ more power to the grid at low wind power than a DFIG without energy storage. This significant additional power boost may determine whether the power system will be able to ride through frequency dips, which are often caused by the loss of generation due to faults within the transmission lines.

\section{ACKNOWLEDGMENT}

This work was supported by the U.S. Department of Energy under Contract No. DE-AC36-08-GO28308 with the National Renewable Energy Laboratory.

\section{REFERENCES}

[1] J. W. Ingleson and E. Allen, "Tracking the Eastern Interconnection frequency governing characteristic," presented at the 2010 IEEE Power and Energy Society General Meeting, Minneapolis, Minnesota.

[2] E. Muljadi, V. Gevorgian, M. Singh, and S. Santoso, "Understanding inertial and frequency response of wind power plants," presented at the IEEE Symposium on Power Electronics and Machines for Wind Applications, Denver, Colorado, July 16-18. NREL/CP-5500-55335. Golden, CO: National Renewable Energy Laboratory, July 2012.

[3] J. H. Eto et al., "Use of frequency response metrics to assess the planning and operating requirements for reliable integration of variable renewable generation," Ernest Orlando Lawrence Berkeley National Laboratory, Berkeley, CA, Tech. Rep., Dec. 2010.

[4] R. Pena, J. C. Clare, and G. M. Asher, "Doubly-fed induction generator using back-to-back PWM converters and its application to variablespeed wind-energy generation," in Proc. 1996 IEEE Electric Power Applications, vol. 143, pp. 231-241.

[5] P. Krause, O. Wasynchzuk, S. Sudhoff, and S. Pekarek, Electric Machinery and Drive Systems, Third Edition, IEEE Press and Wiley, 2013.

[6] W. Gao, E. Muljadi, and X. Wang, "Power capacity specification for energy storage in wind application using probability-based method," in Proc. 2011 IEEE Energy Conversion Congress and Exposition (ECCE), pp. 2,125-2132.

[7] Q. Liyan and Q. Wei, "Constant power control and fault ride-through enhancement of DFIG wind turbines with energy storage," presented at the 2009 Industry Applications Society Annual Meeting, Houston, TX, Oct. 4-8, 2009. 